\title{
Airborne light detection and ranging (LiDAR) point density analysis
}

\author{
José Balsa-Barreiro ${ }^{1}$, Joan Pere Avariento ${ }^{2}$ and José Luis Lerma ${ }^{2^{\star}}$ \\ ${ }^{1}$ Institut Cartogràfic Valencià, C. Santos Justo y Pastor 116, 46022 Valencia, Spain. \\ ${ }^{2}$ Department of Cartographic Engineering, Geodesy and Photogrammetry, Universitat Politècnica de València, \\ Co de Vera, s/n. Edificio 7i. 46022 Valencia, Spain.
}

Accepted 23 July, 2012

\begin{abstract}
The point density is a preeminent parameter on airborne laser scanner surveys. It is not only related to accuracy but costs and savings. The lack of uniformity of the point density across the survey is wellknown in the scientific community. This paper analyzes the behaviour of the point density derived by an oscillating mirror laser scanner on different single strips on flat bare ground in order to estimate a meaningful mean density value. The variation of the point density at both extreme ends of the oscillating mirror scan is meaningful. It will be demonstrated that excluding the extreme sectors across the strip corresponding to $1 / 8$ of the swath width ( $12.5 \%$ of the sampling area, half in each side) for the computation of the mean density value is enough to satisfy light detection and ranging (LiDAR) specifications for national level surveys.
\end{abstract}

Key words: Light detection and ranging (LiDAR), point density, point distribution.

\section{INTRODUCTION}

Airborne laser scanning (ALS) technology, better known as light detection and ranging (LiDAR) is considered one of the best alternatives to obtain digital terrain models (DTMs) with reliable decimeter accuracy (Kraus and Pfeifer, 1998; Axelsson, 2000). Accuracy, high spatial resolution and the ability to penetrate partially through dense vegetation areas are namely the reason for the increasing number of applications of this technology. Over traditional photogrammetry and land surveying, LiDAR technology offers high accuracy, fast acquisition and processing time with minimum human dependence (Gungor et al., 2010). LiDAR DTMs can be used as input GIS data for analysis, monitoring and simulation tasks (Lohr and Droesen, 1997; Raber et al., 2007; Wang et al., 2008), and specially for vegetation/biomass studies (Hall et al., 2005; Huang et al., 2009; Estornell et al., 2010; Jochem et al., 2011; Llorens et al., 2011).

The desired number of points per unit area is set

${ }^{*}$ Corresponding author. E-mail: jllerma@cgf.upv.es. Tel: +34 963877550. Fax: +34 963877559. depending on the purpose of the LiDAR mission, for example, detailed $3 \mathrm{D}$ models of urban areas, flood-risk maps, vegetation-cover analysis, etc. This value fixes the level of detail that can be extracted from the LiDAR data (Triglav-Cekada and Crosilla, 2009). For countrywide models, the point density that is currently used is around 0.5 to 1 point $/ \mathrm{m}^{2}$ (Artuso et al., 2003); more demanding densities are required for example, for biomass studies and tree modeling (Wang et al., 2008; Llorens et al., 2011). More than 7 to 8 points $/ \mathrm{m}^{2}$ do not yield a significant improvement when computing the DTM accuracy. Higher densities (8 to 10 points $/ \mathrm{m}^{2}$ ) are only recommended for dense vegetation areas (Reutebuch et al., 2003; Chasmer et al., 2006).

Several factors are important when choosing the flight parameters for the LiDAR mission: purpose, accuracy, field conditions and savings. Increasing the height of the flight is the most frequent way to reduce data acquisition costs. Increasing the height of the mission, the density decreases as well as the accuracy, and the size of the footprint increases whether the pulse rate is kept constant (Yu et al., 2004; Hyyppä et al., 2005). However, LiDAR flights with new systems allow providers to 


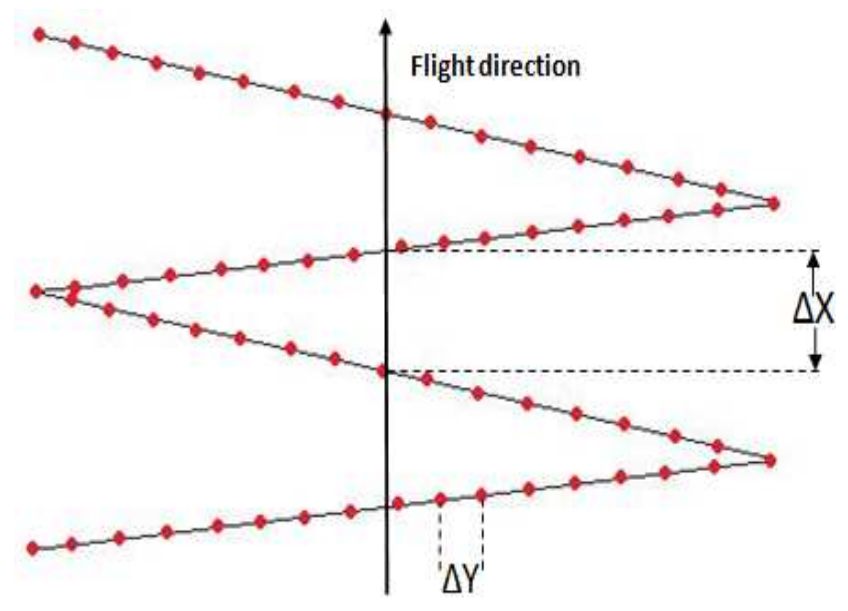

Figure 1. Theoretical zigzag pattern over the ground produced by an oscillating mirror laser scanner.

achieve the same density with lower costs (Ahokas et al., 2005).

Point density on the ground is determined by the aircraft speed, scan angle, pulse rate, scan rate, altitude and sensor drift (Axelsson, 2000; Kukko and Hyyppä, 2009). Point density is considered one of the factors that affect DTM altimeter accuracy: with higher density, the resolution increases as well as the accuracy of the DTM (Hodgson and Bresnahan, 2004; Su and Bork, 2006; Aguilar et al., 2010). On the other hand, a low density implies more separation between points, degrading the accuracy in the point interpolation (Su and Bork, 2006).

$A$ reduction in the density, that is, an increase in the point-spacing, influences the accuracy of the DEM: the errors increase when the density decreases (Liu et al., 2007). The point-spacing is the major contributor to the vertical error in LiDAR-derived DEM (Hodgson and Bresnahan, 2004). An empirical relationship between point-spacing and the accuracy of the DEM is established in Raber et al. (2007). DEM accuracy is also affected by the regularity of the points altogether with the density (Artuso et al., 2003; Raber, 2003). Estornell et al. (2010) confirmed that the DTM accuracy is also affected by the window size of the interpolation algorithm, the height thresholds and several effects such as slope, point density and vegetation. Su and Bork (2006) reported that the scan angle has relatively little impact on the DEM accuracy.

Many authors studied the effects of vegetation density in reference to point density and DEM accuracy. Dense vegetation reduces the number of returns on the ground (Ahokas et al., 2005; Yu et al., 2005). The higher the LiDAR point density is used, the deeper the penetration into vegetation is possible (Triglav-Cekada and Crosilla, 2009). Furthermore, point density has more influence than the size of the footprint to determine tree heights (Persson et al., 2002; Yu et al., 2004).
Point density is paramount for LiDAR surveys. It is not only related to accuracy but costs and savings. Small point-spacing requires higher frequency sensor flying at a lower altitude, narrower field of view (FOV) and slower speed, or a combination of these. In short, more flight (strip) lines are required, more operators and resources.

LiDAR specifications at national level set that a percentage of the swath width should be excluded when planning the aerial mission. But there is no quorum. For instance, the technical specifications for the digital photogrammetric flight with LiDAR in Spain for the National plan of aerial orthophotography (PNOA) set a value of $2 \%$ for the first return, single swath; the draft document for the LiDAR guidelines and base specification from the United State Geological Survey set an approximate value of $10 \%$ (USGS, 2010). Besides the expected uniform spatial distribution of geometrically usable points, the latter document also specifies that the distribution should be free from clustering.

In this study, the spatial variation of the point density across single strips is statically reported and analyzed. Some recommendations are presented in order to estimate accurately the mean density value of LiDAR surveys.

\section{OSCILLATING MIRROR MECHANISM AND GROUND MEASURING PATTERN}

There are several types of laser scanner mechanism: Rotating polygon, oscillating mirror, mirror palmer and fiber optic (Wehr and Lohr, 1999). Oscillating mirror is the mechanism that will be analyzed next.

The oscillating mirror produces a zigzag pattern (Figure 1) due to the bidirectional scanning mechanism. The output is an irregular pattern with smaller point spacing across the strip than along the strip. The sampling of the LiDAR-based points on the ground is more homogeneous along the center of the flight line than in the borders.

Factors that influence the pattern of the scan are: The flight speed, the scan, and last but not least, the topography; the first two parameters lead to a reduction of the distance between points along the strip (Kukko and Hyyppä, 2009). Points found in the same line are usually scanned with an equal increase in angle, but the pointspacing is not constant on the ground. This is due to acceleration or deceleration of the internal mirror and the slope of the ground. The points at the edges have different characteristics and so are often discarded from the raw data (Wehr and Lohr, 1999).

Some theoretical formulas and relationships for airborne laser scanners with oscillating mirror can be found in Baltsavias (1999), assuming that the points have equal distance between them in a single scan line and that the scanning speed is constant. The point density per unit area can be defined as a function of pulse rate, flying time per strip and covered area. 
Table 1. Characteristics of the Leica Geosystems ALS60 system.

\begin{tabular}{ll}
\hline Wavelength & $1064 \mathrm{~nm}$ \\
Pulse length & $5 \mathrm{~ns}$ \\
Scanning method & Oscillating mirror \\
Scan rate & $100 \mathrm{~Hz}$ \\
Pulse rate & $20-200 \mathrm{KHz}$ \\
Field of view (FOV) & $75^{\circ}$ \\
Echoes per pulse & 4 echoes or Full waveform \\
Laser beam & 0.15 mrad at 1/e \\
Intensity dynamic range & 8 bits \\
Flight height & $200-5000 \mathrm{~m}$ \\
\hline
\end{tabular}

Table 2. Flight parameters.

\begin{tabular}{ll}
\hline System & ALS60 \\
FOV & $50^{\circ}$ \\
Flight altitude & $2600-3070 \mathrm{~m}$ \\
Flight speed & $100-150 \mathrm{kn}$ \\
Scan rate & $33.7 \mathrm{~Hz}$ \\
Pulse rate & $93900 \mathrm{~Hz}$ \\
INS: & IMU POS-AV 510 \\
GNSS: & NovAtel MILLENIUM at $0.1 \mathrm{~Hz}$ \\
\hline
\end{tabular}

\section{STUDY AREA AND LIDAR DATA ACQUISITION}

The analysis of the spatial distribution of the point density from airborne LIDAR data was tested in the province of Castellón (Spain). It was surveyed between August and November 2009 for the PNOA project using a Leica Geosystems ALS60 system (Table 1). According to the technical specifications of the mission, the average density should be better than 0.5 points per $\mathrm{m}^{2}$, the horizontal precision should be better than $30 \mathrm{~cm}$ and the vertical one better than $20 \mathrm{~cm}$ (RSME). A total of 355 strips were acquired for the whole province. The flight features of the ALS survey are presented in Table 2.

Five representative samples were extracted from five strips (Figure 2). The swath width was approximately $2200 \mathrm{~m}$, the maximum swath width at a $50^{\circ} \mathrm{FOV}$, while its length was set up to $200 \mathrm{~m}$. Samples were selected on flat bare ground in order to minimize the influence of the topography. In addition, areas with man-made structures (namely building and bridges) and tall vegetation were excluded. The sampling areas were selected to minimize the number of returns for the laser pulses and maximize the density of points. Single strips were considered to avoid oversampling in overlapping areas.

\section{RESULTS AND STATISTICAL ANALYSIS}

Knowing the zigzag laser scanning pattern of the ALS system on the ground, every strip was divided across into 16 sectors (polygons) with equal angular increments $\left(3.125^{\circ}\right)$, starting from the centre of each strip to the left $(\mathrm{L})$ and to the right $(\mathrm{R})$ (Figure 3 ).
As stated in Vosselman and Klein (2010), much information can be retrieved from point density images. These images are obtained by counting the number of points within a cell. Figure 4 displays a point density image corresponding to one strip, categorized in six classes ranging from 0 points up to $1,2,3$ to 10,11 to 25 and more than 26 points per cell, with a cell size of $2 \times 2$ $\mathrm{m}$. Figure 4 reveals the lack of homogeneity of the LiDAR points across the strip: in the centre there is a small number of points per cell but the sampling is approximately even; the number of points increases from the centre up to both sides (extremes); nearby the extremes of the swath width the number of points increases drastically. The output is an odd distribution of points across the strip, more and less symmetric along the strip. In short, most of the points are concentrated in the extremes (cf. the large number of points in FOV41) while in the centre (FOV10 left and right) the number of points is considerably modest. Subsequently, the study will try to confirm statistically the influence of the point sampling on the computation of the overall density across the strips.

Table 3 shows the point density values over the bare ground computed for each sector across the five strips (Figures 5 and 6 displays a graphical representation of Table 3). The mean point densities range from 0.36 points $/ \mathrm{m}^{2}$ in the centre up to 1.345 points $/ \mathrm{m}^{2}$ in the borders of the strip. Worth noticing is the range of values for the standard deviation, ranging from 0.025 points $/ \mathrm{m}^{2}$ in the centre up to 0.07 points $/ \mathrm{m}^{2}$ in the borders. For both parameters (mean and standard deviation), a clear difference in magnitude is presented for both borders, keeping the rest of the sectors values close to the ones at the centre, that is, fourteen out of the sixteen sectors keep density values close to each other.

Figure 5 displays the point densities for the different sectors of the five strips and the mean; the mean value is represented by the dash line. In general, the point density remains relatively constant in the central part of the strip while in the borders of the flight lines the point density increases exponentially, which increases the overall mean density of the whole strips.

Figure 6 simplifies the density values across the FOV and adds the standard deviation to focus the attention in both extreme values, FOV41L and FOV41R: not only the mean density values differ substantially but also the standard deviations. Furthermore, both left and right sides are approximately symmetric as expected theoretically a priori.

Considering the 80 sampling areas (16 sectors $\times 5$ strips), the mean density yields a value of 0.536 points $/ \mathrm{m}^{2}$. Only FOV40 and FOV41 present higher densities, that is, four intervals out of sixteen. Therefore, only $25 \%$ of the surface of the test strips has a density greater than the mean value, but the most extreme sector (FOV41), which represents only $12,5 \%$ of the surface of the strip, clearly exceeds by far (2.5 times) the mean 


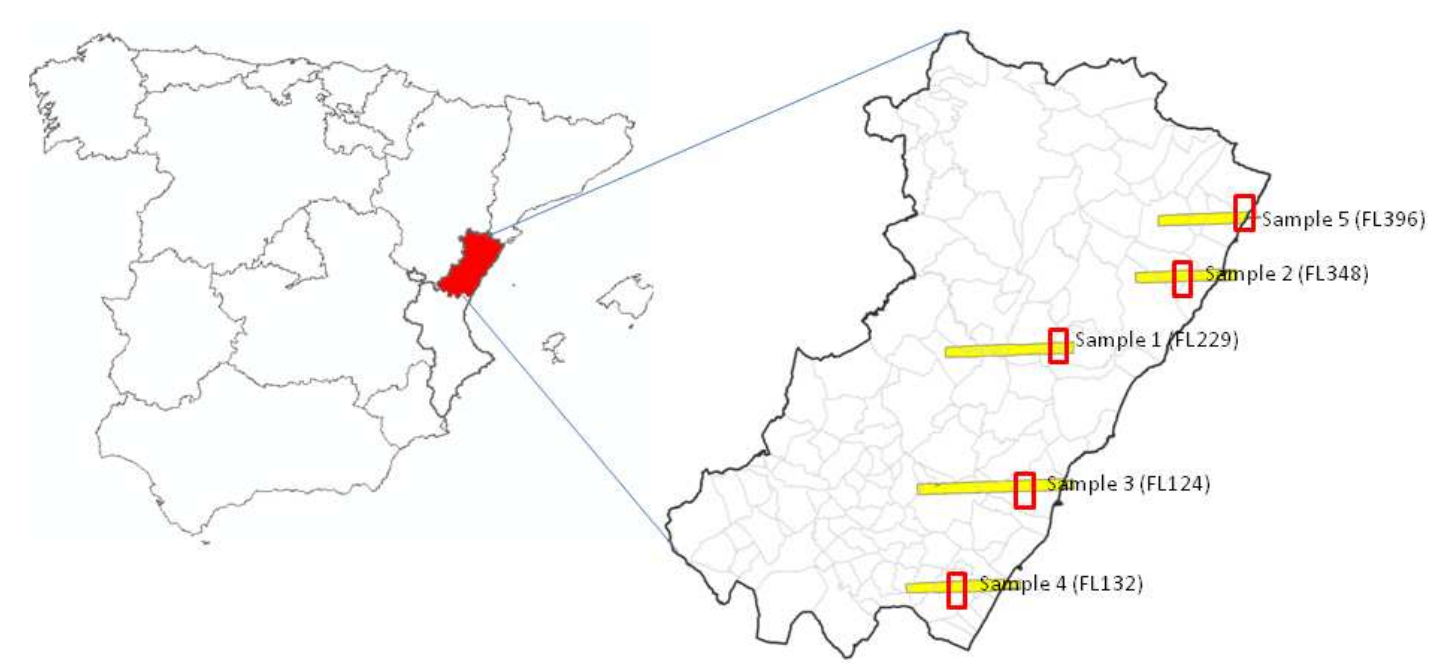

Figure 2. Sampling areas with indication of the original flight lines (FL).

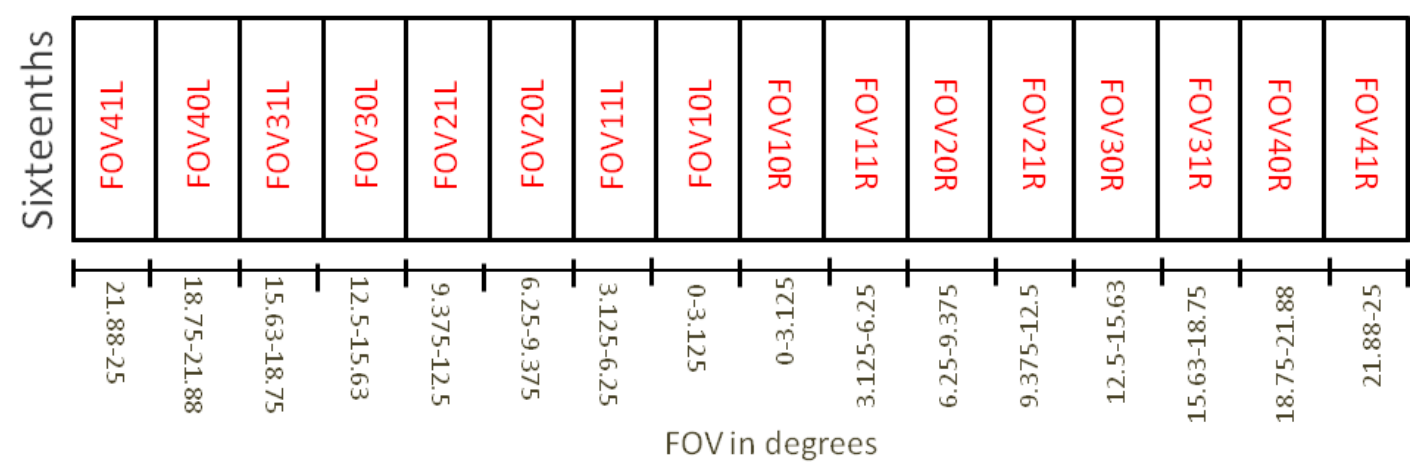

Figure 3. Sectors across the swath width used to analyse the density.

point density. Recalculating the statistics for the data set with and without FOV41 extreme sector, the following results are obtained (Table 4 and Figure 7).

Without considering FOV41 in the computation of the density of points, the mean value drops 0.12 units, from 0.54 to 0.42 points $/ \mathrm{m}^{2}$. Second, the standard deviation drops more than four times, from 0.32 to 0.075 points $/ \mathrm{m}^{2}$. The 'Box and Whisker' diagrams (Tukey, 1977; Frigge et al., 1989; Sheskin, 2007; Banacos, 2011) in Figure 7 clarify the interpretation and confirm the smooth continuity in the computation of the range of density values per sector.

At this point, the question arises whether the density values follow a normal (Gaussian) distribution or not. As previously confirmed, the left and right extreme sectors of the strips concentrate most of the points in a very small FOV range. Therefore, points belonging to both sectors might probably "break" the normality of the sample (Silverman, 1986). This observation will be confirmed next.

The normal tendency of the distribution function of the data can be analyzed with the normal probability plots with and without FOV41 data (Figure 8). The continuous line up represents a normal function. Once the FOV41 values are discarded (right chart Figure 8), the sample of point densities is much closer to a normal distribution function. In fact, Dixon (1950), Grubbs and Beck (1972) and Iglewicz and Hoaglin (1993) tests confirmed the lack of outliers within the data with a confidence level of $99 \%$. Therefore, both sectors FOV41 (FOV41L and FOV41R) can be considered outliers and should be rejected when computing the mean point density of the survey.

Complementary data to the one presented in Figure 8 is undertaken, studying the accumulated frequencies from the range of density values. Figure 9 displays the accumulated frequency histograms of both solutions with and without the extreme sectors FOV41L and FOV41R. Figure 9a shows that there are two distributions, one with density values up to 0.64 that accumulates up to $87.5 \%$ of the frequency (black line) and $68.74 \%$ of the total points, and another small set of density values ranging from 1.24 to 1.43 that concentrates only the remaining 


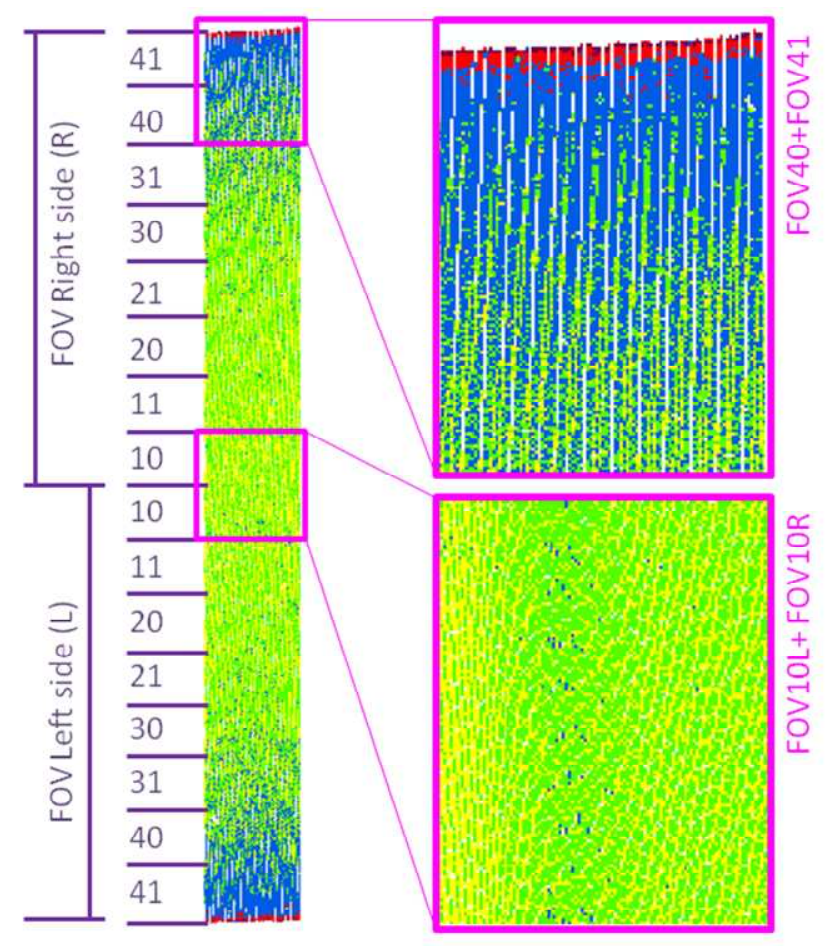

(a)

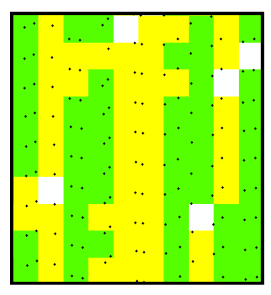

FOV10

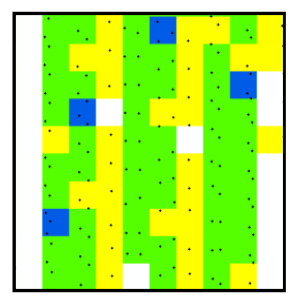

FOV21 (b)

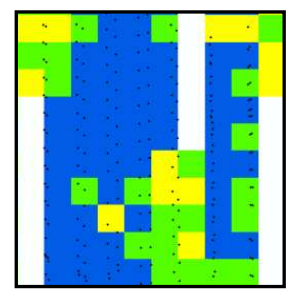

FOV40

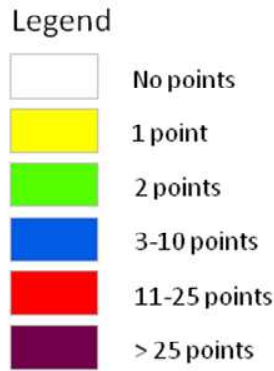

Raster grid size $=2$ meters

(c)

Figure 4. Varying number of LiDAR points across a strip: (a) swath width divided by sectors; (b) corresponding points in central area (FOV10L+FOV10R) and extreme (FOV40R+FOV41R); (c) zoom into four patches.

Table 3. Density values (points $/ \mathrm{m}^{2}$ ) for the sixteen sampling areas together with the mean and standard deviation.

\begin{tabular}{|c|c|c|c|c|c|c|c|c|c|c|c|c|c|c|c|c|c|}
\hline \multirow{2}{*}{$\begin{array}{c}\text { Flight line } \\
\text { (FL) }\end{array}$} & \multirow{2}{*}{ Sample } & \multicolumn{16}{|c|}{ FOV (Position-side) } \\
\hline & & $41 \mathrm{~L}$ & $40 \mathrm{~L}$ & $31 \mathrm{~L}$ & $30 \mathrm{~L}$ & $21 \mathrm{~L}$ & $20 \mathrm{~L}$ & $11 \mathrm{~L}$ & $10 \mathrm{~L}$ & 10R & 11R & 20R & 21R & 30R & 31R & 40R & 41R \\
\hline 229 & 1 & 1.29 & 0.56 & 0.45 & 0.41 & 0.38 & 0.36 & 0.36 & 0.35 & 0.36 & 0.36 & 0.37 & 0.38 & 0.41 & 0.46 & 0.57 & 1.30 \\
\hline 348 & 2 & 1.41 & 0.54 & 0.47 & 0.44 & 0.40 & 0.36 & 0.36 & 0.33 & 0.34 & 0.35 & 0.38 & 0.42 & 0.43 & 0.46 & 0.55 & 1.38 \\
\hline 124 & 3 & 1.26 & 0.53 & 0.44 & 0.37 & 0.37 & 0.36 & 0.34 & 0.34 & 0.34 & 0.35 & 0.36 & 0.36 & 0.38 & 0.44 & 0.52 & 1.24 \\
\hline 132 & 4 & 1.34 & 0.58 & 0.49 & 0.40 & 0.38 & 0.38 & 0.37 & 0.36 & 0.36 & 0.36 & 0.37 & 0.37 & 0.41 & 0.46 & 0.56 & 1.33 \\
\hline 396 & 5 & 1.43 & 0.64 & 0.52 & 0.47 & 0.44 & 0.42 & 0.41 & 0.40 & 0.40 & 0.40 & 0.41 & 0.43 & 0.45 & 0.51 & 0.63 & 1.43 \\
\hline \multicolumn{2}{|c|}{ Mean density $(\mu)$} & 1.35 & 0.57 & 0.47 & 0.42 & 0.39 & 0.38 & 0.37 & 0.36 & 0.36 & 0.36 & 0.38 & 0.39 & 0.42 & 0.47 & 0.57 & 1.34 \\
\hline \multicolumn{2}{|l|}{$\operatorname{SD}(\sigma)$} & 0.07 & 0.04 & 0.03 & 0.04 & 0.03 & 0.03 & 0.03 & 0.03 & 0.02 & 0.02 & 0.02 & 0.03 & 0.03 & 0.03 & 0.04 & 0.07 \\
\hline
\end{tabular}




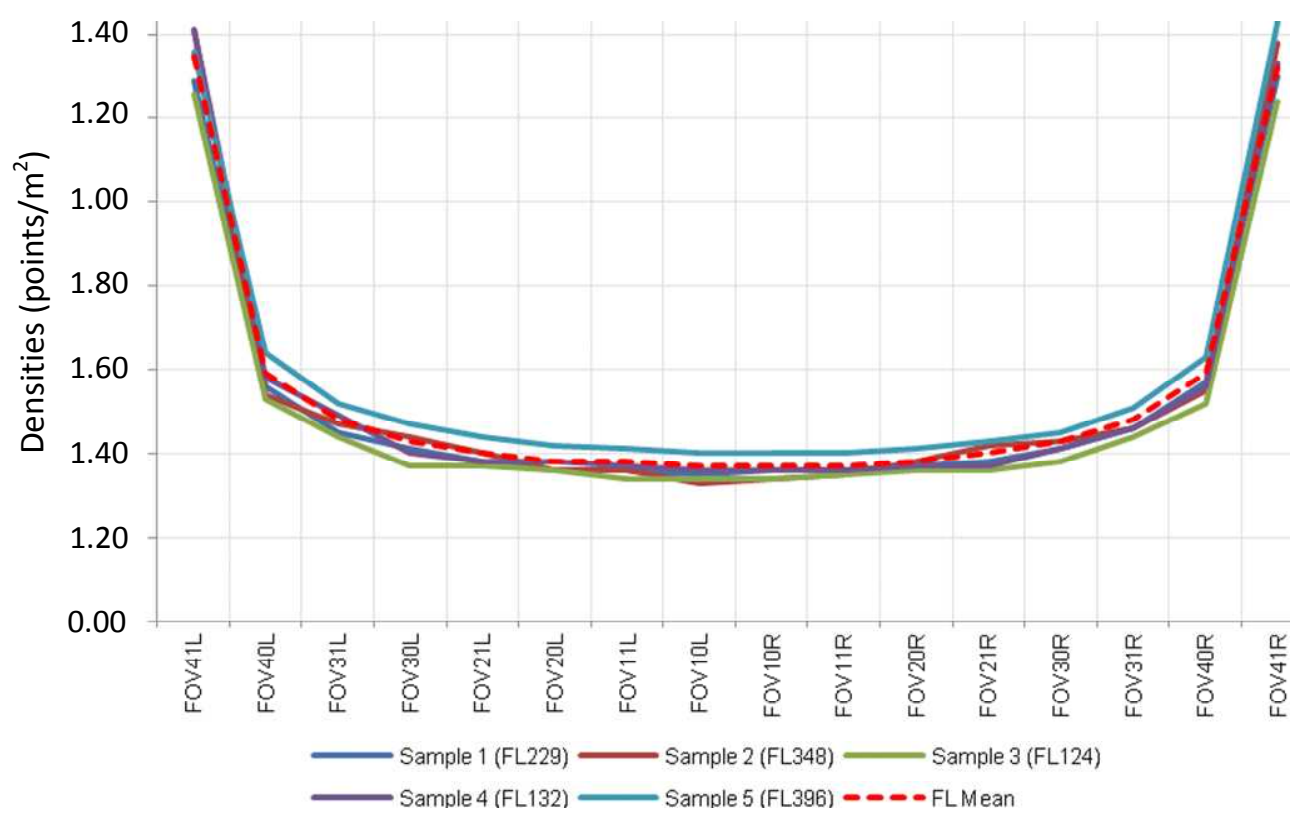

Figure 5. Profiles of the densities (points $/ \mathrm{m}^{2}$ ) across the FOV for the five sampling strips.

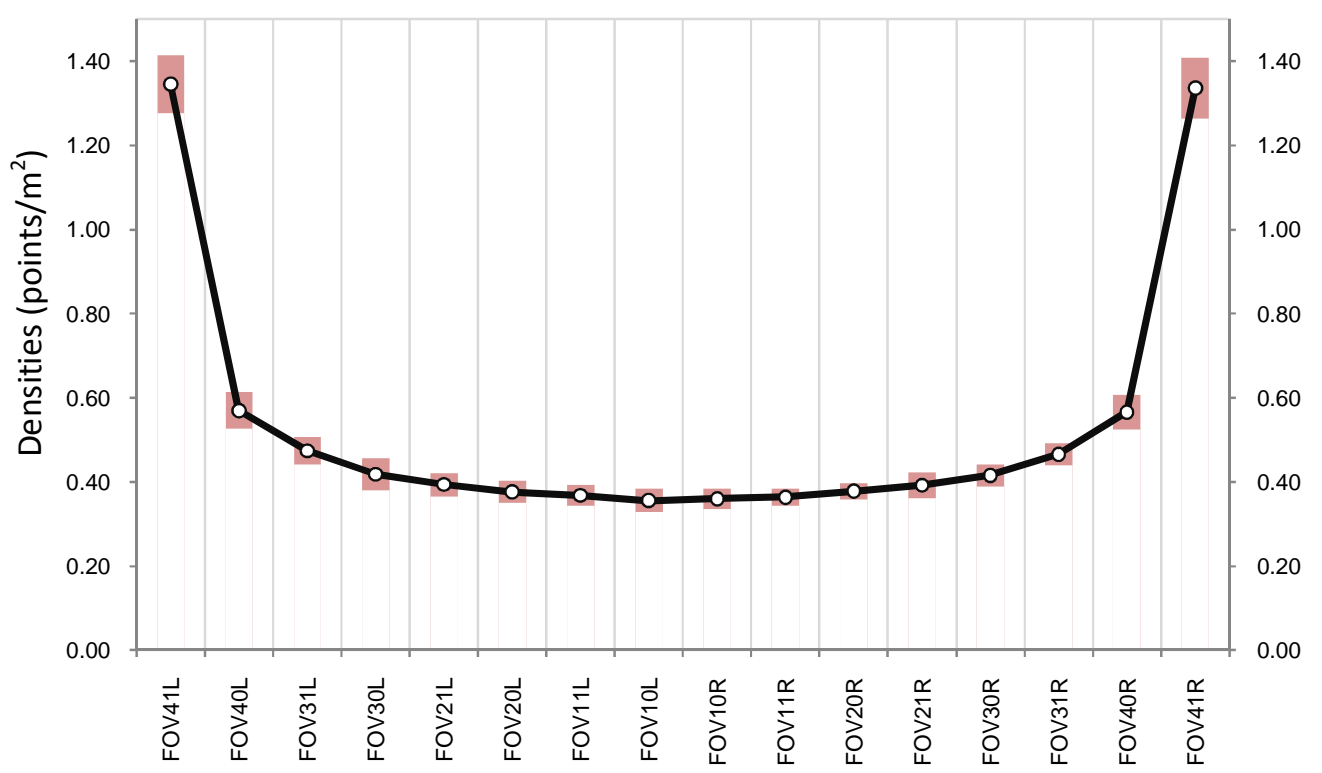

Figure 6. Profile of the mean densities (points $/ \mathrm{m}^{2}$ ) and the standard deviations across the FOV.

Table 4. Summary of statistics with all the sixteen sampling areas, and all but the extremes FOV41L and FOV4R (fourteen sampling areas).

\begin{tabular}{lcc}
\hline Statistic & All the sixteen samples & Fourteen samples excluding FOV41 \\
\hline Frequency & 80 & 70 \\
Mean density $\left(\right.$ points $\left./ \mathrm{m}^{2}\right)$ & 0.536 & 0.421 \\
Standard deviation $\left(\right.$ points $\left./ \mathrm{m}^{2}\right)$ & 0.315 & 0.075 \\
\hline
\end{tabular}



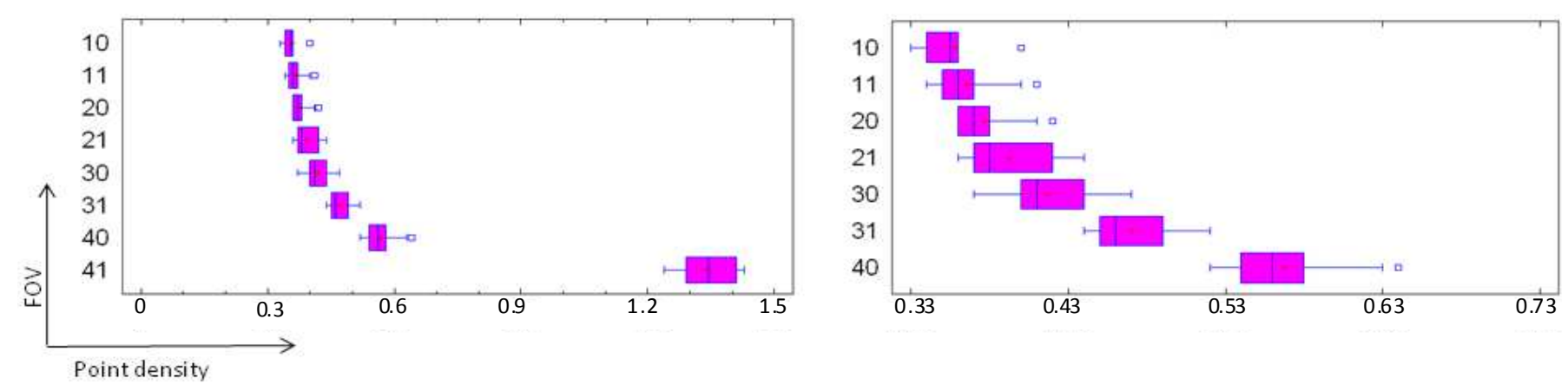

Figure 7. Box and Whisker diagram obtained for each sector, considering all the sectors (left chart) and all but FOV41 (right chart). It is worth noticing the longer $\mathrm{x}$-axis for the former than for the latter.
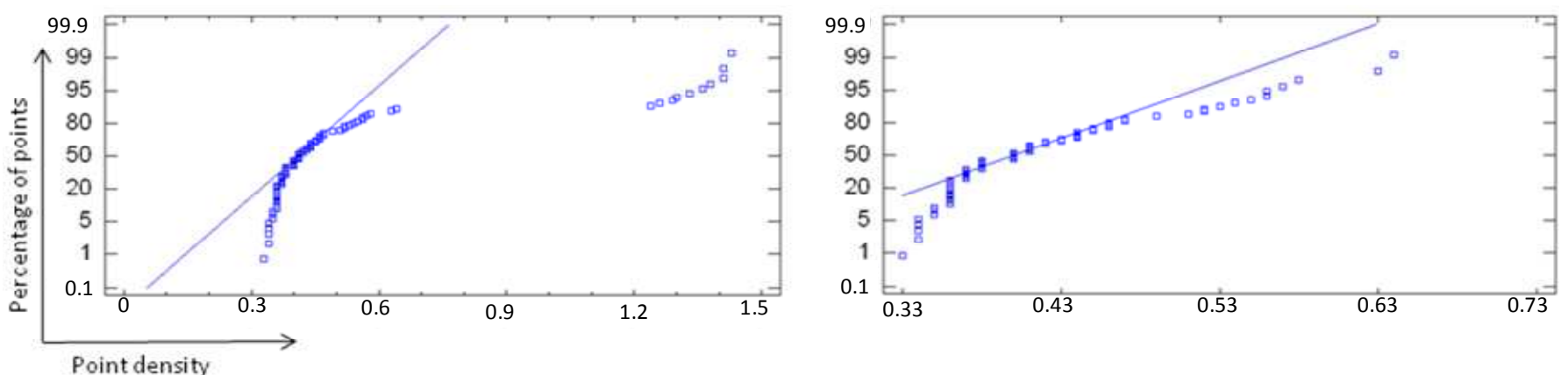

Figure 8. Normal probability plots obtained for each sector, considering all the sectors (left chart) and all but FOV41 (right chart).

$12.5 \%$ of the frequency. Overall, it is expected that after excluding FOV41 (Figure 9b), only one distribution of points ranging from 0.33 to 0.64 will have a frequency up to $100 \%$. In both diagrams, there is no data below a point density value of 0.33 .

\section{DISCUSSION}

It is well-known that one of the most important parameters when planning a LiDAR campaign is the point density. The final goal is to obtain the right amount of points throughout the survey area. A homogeneous density of points allows the extraction of more information, decreasing the gaps (areas without information) and modeling the ground surface in a way that is more reliable and more accurate (Gomes-Pereira and Janssen, 1999; Sanii, 2008; Pirotti and Tarolli, 2010; Puetz et al., 2009).

More important than the overall density of points per area is the homogeneous density over the bare ground. A homogeneous distribution of the points over the bare ground allows users to have a full sampling of the ground. However, it is not clear the geometrically usable centre portion of each swath, for example, $98 \%$ for PNOA and $90 \%$ for USGS; this study confirms $87.5 \%$ which is closer to the USGS despite the survey was ordered for PNOA.

In this study, the LiDAR point density and its distribution pattern on five samples from different lines of flight is empirically analyzed considering true data. From the analyzed samples, it can be inferred that the density of points from LiDAR surveys with oscillating mirrors is not homogeneous across the strip, but rather irregular. However, the lack of uniformity in the spatial distribution of points is higher than expected from LiDAR textbooks. In fact, the ideal pattern of a LiDAR oscillating mirror that is presented in Figure 1 (as well as others such as the ones presented by Petrie and Toth, 2009) about the shape of the oscillating mirror mechanisms is not correct, and should be accordingly corrected based on the shape presented in Figure 4. This figure emphasizes the irregular point cloud pattern over the ground. Both extremes concentrate a large number of points because of the oscillating mirror that speeds up and decelerates for each scan line. Therefore, there is a high accumulation of points at the borders across track but with a significant space of points along the strip. In other words, $\Delta y$ tends to minimum (almost zero) and $\Delta x$ tends to maximum yielding cells without any point at the extremes for a FOV of 50을 (Figure $4 \mathrm{~b}$ and c).

Higher concentration of points across the strip is 


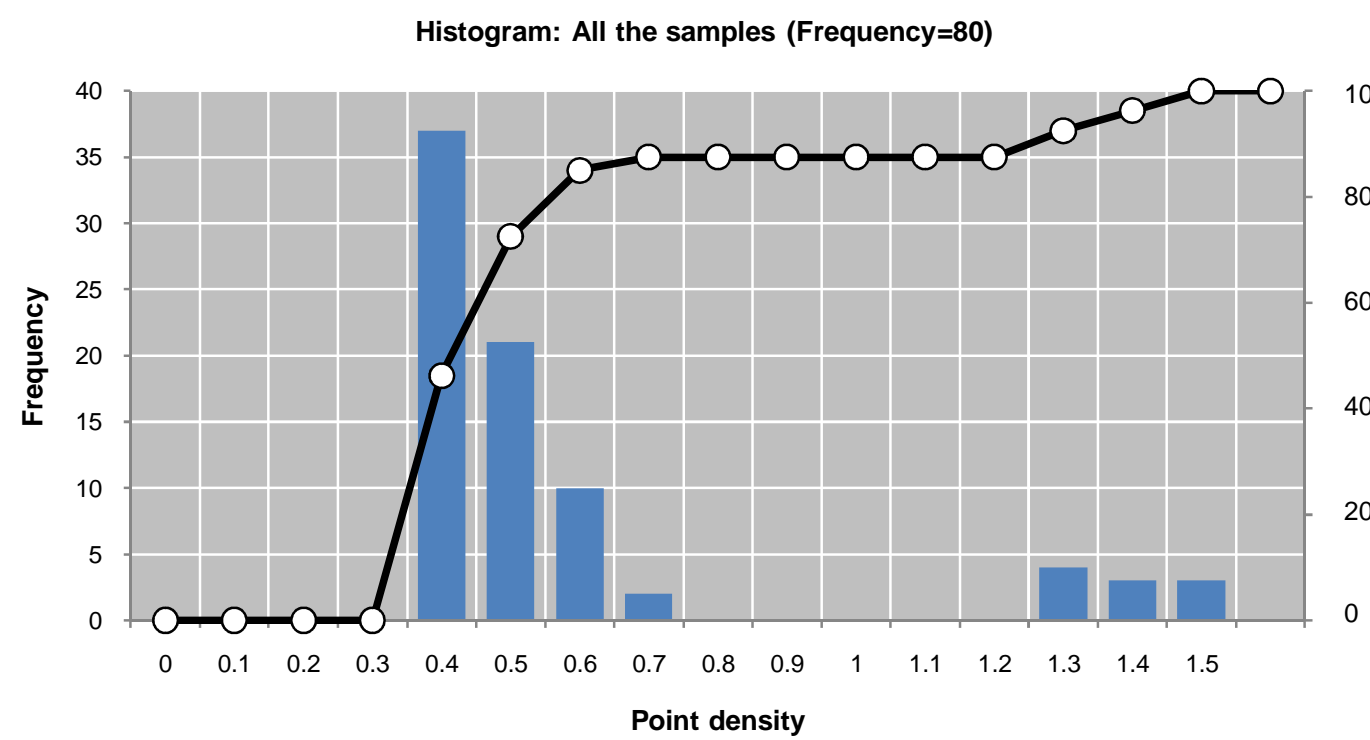

(a)

Histogram: All the samples but FOV41 (Frequency=70)

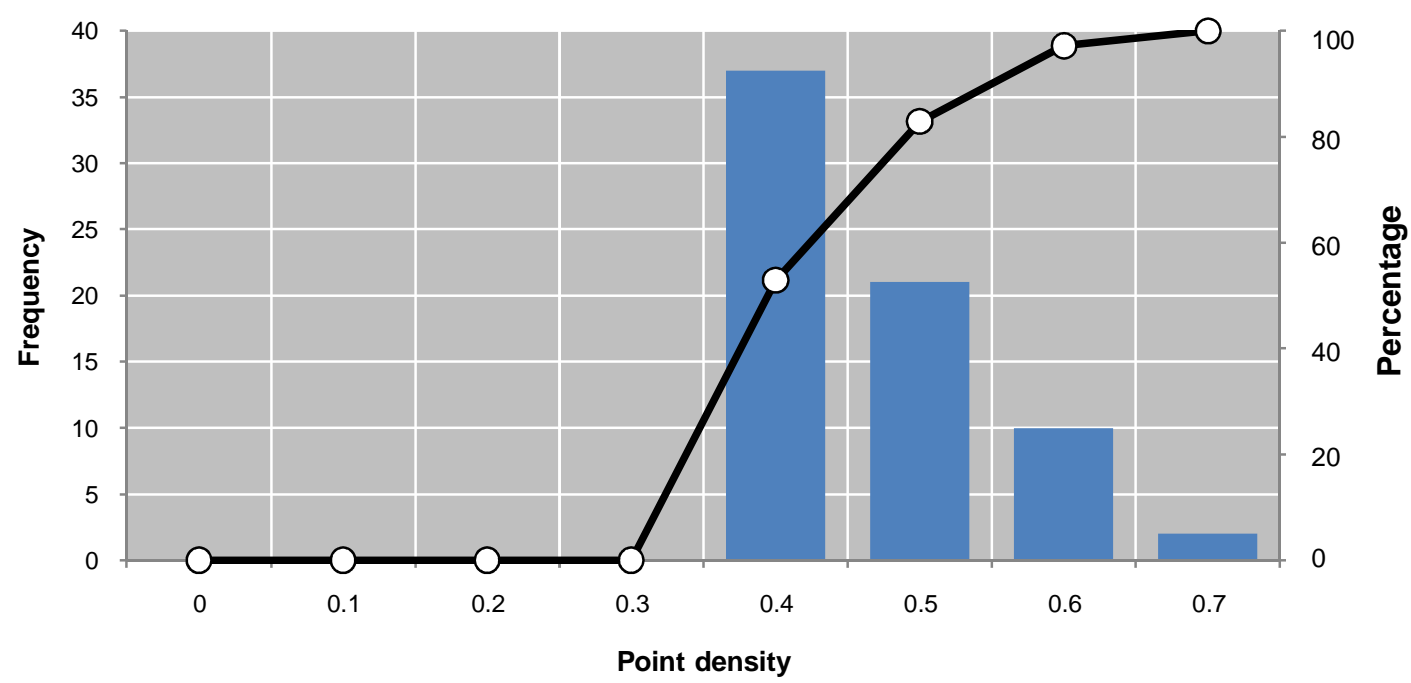

(b)

Figure 9. Accumulated frequency histograms considering all the sectors (a); and all but FOV41 (b).

expected for larger FOVs, affecting negatively the computation of the mean data density. This study demonstrates empirically that an appropriate FOV should be $43.75^{\circ}$. With a right estimation of the mean point density, analytical studies can be conducted more precisely based on collateral effects such as quality and precision of LiDAR-based DTMs (Gomes-Pereira and, Janssen, 1999; Sanii, 2008).

The irregular pattern distribution of LiDAR points with oscillating mirrors, especially when referring to both extreme sectors (FOV41L and FOV41R), has a number of important effects on the data processing. Whenever dealing with single LiDAR strips, the laser scanning point cloud will not have the expected results owing to the odd distribution of points (Figure 4) in spite of satisfying the requirements of average point density, for example, either with overlapping strips or with cross strips.

Regarding blocks with several strips, it is worth mentioning that the overlaps between strips are in the extreme sectors where the highest point densities are expected. Therefore, the average density of LiDAR points will be increased for the whole study area, but the distribution of points across the strips will be more irregular: the extreme sectors that concentrate more points on single strips will double the point densities across the FOV in the overlapping areas while the rest 
will keep the same point density values.

\section{Conclusions}

Point density is a relevant parameter in airborne LiDAR missions and surveys. Collateral effects such as quality and precision, and deliverables such as DSMs and DTMs, vegetation and biomass studies depend to a large extent on point density. Users and providers rely on its mean value either for planning or for post-processing. This paper presents an empirical study reflecting the large variability of point density values across the swath width when using an oscillating mirror laser scanning mechanism. The study is focused on flat bare ground areas to determine the mean point density of an airborne LiDAR survey. The spatial distribution pattern of LiDARbased points is also analyzed across single strips.

Significant differences when computing the point density values across the strip are achieved. Statistical analysis shows that the extreme sectors (FOV41L and FOV41R), which represents only $12.5 \%$ of the swath width, clearly exceed 2.5 times the mean point density. This study demonstrates empirically that oscillating mirror-based LiDAR systems do not follow a normal (Gaussian) distribution of point densities. Both extreme sectors on $50^{\circ}$ FOV systems, FOV41L and FOV41R in this study, can be considered as outliers with a confidence level of $99 \%$. Both sectors should be rejected when computing the mean point density value of an airborne LiDAR survey. It means that for a $50^{\circ} \mathrm{FOV}$ oscillating mirror system, the usable centre portion of each swath width free from clustering should be $87.5 \%$ that is, $43,75^{\circ}$ FOV. Therefore, the exclusion of an area of $12.5 \%$ is close to what specifies the United States Geological Survey but far away the $2 \%$ specified for the Spanish PNOA.

As different laser scanning mechanisms exist on the LiDAR market, future research on point density is expected to deal with different LiDAR systems as well as on more complex scenarios with diverse degree of vegetation, slope and cover.

\section{REFERENCES}

Aguilar FJ, Mills JP, Delgado J, Aguilar MA, Negreiros J, Pérez JL (2010). Modelling vertical error in LiDAR-derived digital elevation models. ISPRS J. Photogramm. 65:103-110.

Ahokas E, Yu X, Oksanen J, Hyyppä J, Kaartinen H, Hyyppä H (2005). Optimization of the scanning angle for countrywide laser scanning. In: International Archives of Photogrammetry, Remote Sensing and Spatial Information Sciences. Enschede, Netherlands 36(3/ W19):115-119.

Artuso R, Bovet S, Streilein A (2003). Practical methods for the verification of countrywide terrain and surface models. In: International Archives of the Photogrammetry. Remote Sens. Geoinform. Sci. 34(3/W13):14-19.

Axelsson $P$ (2000). DEM generation from laser scanner data using adaptative TIN models. In: Int. Arch. Photogramm. Remote Sens. 33(Part B4):110-117.
Baltsavias E (1999). Airborne laser scanning: basic relations and formulas. ISPRS J. Photogramm. 54(2-3):199-214.

Banacos PC (2011). Box and whisker plots for local climate datasets: Interpretation and creation using Excel 2007/2010. NWS Eastern Region Technical Attachment 2011(01), National Weather Service, Ed: Eastern Region Headquarters, Bohemia, New York, USA.

Chasmer L, Hopkinson C, Treitz P (2006). Investigating laser pulse penetration of a conifer canopy through the integration of airborne and terrestrial LiDAR. Can. J. Remote Sens. 32(2):116-125.

Dixon WJ (1950). Analysis of extreme values. Ann. Math. Stat. 21(4):488-506.

Estornell J, Ruiz L, Velázquez-Martí B, Hermosilla T (2010). Analysis of the factors affecting LiDAR DTM accuracy in a steep shrub area. Int. J. Dig. Earth 4(6):521-538.

Frigge M, Hoaglin DC, Iglewicz B (1989). Some implementations of the boxplot. Am. Stat. 43(1):50-54.

Gomes-Pereira LM, Janssen LLF (1999). Suitability of laser data for DTM generation: a case study in the context of road planning and design. ISPRS J. Photogramm. Remote Sens. 54(4):244-253.

Grubbs FE, Beck G (1972). Extension of sample sizes and percentage points for significance tests of outlying observations. Technometrics 14(4):847-854.

Hall S, Burke I, Box D, Kaufmann M, Stoker J (2005). Estimating stand structure using discrete-return lidar: an example from low density, fire prone ponderosa pine forests. For. Ecol. Manage. 208:189-209.

Hodgson ME, Bresnahan P (2004). Accuracy of airborne LiDAR-derived elevation: empirical assessment and error budget. Photogramm. Eng. Remote Sens. 70(3):331-339.

Huang H, Gong P, Cheng X, Clinton N, Li Z (2009). Improving measurement of forest structural parameters by co-registering of high resolution aerial imagery and low density LiDAR data. Sensors 9:1541-1558.

Hyyppä H, Yu X, Hyyppä J, Kaartinen H, Kaasalainen S, Honkavaara E, Rönnholm P (2005). Factors affecting the quality of DTM generation in forested areas. In: ISPRS Workshop-Laser Scanning, Enschede, Netherlands: WG III/3, III/4, V/3, pp. 85-90.

Iglewicz B, Hoaglin DC (1993). How to Detect and Handle Outliers. Ed: American Society for Quality Control: Milwaukee, Wisconsin, USA.

Jochem A, Hollaus M, Rutzinger M, Höfle B (2011). Estimation of aboveground biomass in alpine forests: A semi-empirical approach considering canopy transparency derived from airborne LiDAR Data. Sensors 11:278-295.

Kraus K, Pfeifer N (1998). Determination of terrain models in wooded area with airborne laser scanner data. ISPRS J. Photogramm. 53(4):193-203.

Kukko A, Hyyppä J (2009). Small-footprint laser scanning simulation for system validation, error assessment and algoritm development. Photogramm. Eng. Remote Sens. 75(9):1177-1189.

Liu X, Zhang Z, Peterson J, Chandra S (2007). The effect of LiDAR data density on DEM accuracy, In: International Congress on Modelling and Simulation, Christchurch, New Zealand. pp.1363-1369.

Llorens J, Gil E, Llop J, Queraltó M (2011). Georreferenced LiDAR 3D vine plantation map generation. Sensors 11:6237-6256.

Lohr U, Droesen W (1997). TopoSys topographical base data. EARSel Newslett. 32:15-18.

Persson A, Holmgren J, Söderman U (2002). Detecting and measuring individual trees using an airborne laser scanner. Photogramm. Eng. Remote Sens. 68(9):925-932.

Petrie G, Toth CK (2009). Airborne and spaceborne laser profilers and scanners. In: Topographic Laser Ranging and Scanning, Shan J, Toth CK, Ed: CRC Press, United States of America. pp. 29-85.

Pirotti F, Tarolli $P$ (2010). Suitability of LiDAR point density and derived landform curvature maps for channel network extraction. Hydrol. Process. 24:1187-1197.

Puetz AM, Olsen RC, Anderson B (2009). Effects of LiDAR point density on bare earth extraction and DEM creation. In: Laser Radar Technology and Applications, XIV Proceedings of the SPIE 7323: 73230l-732308.

Raber G (2003). The effect of LiDAR posting density on DEM accuracy and flood extent delineation, In: Proceedings of the UCGIS Summer Assembly, Pacific Grove, California, USA.

Raber $G$, Jensen JR, Hodgson ME, Tullis JA, Davis BA, Berglund J 
(2007). Impact of LiDAR nominal post-spacing on DEM accuracy and flood zone delineation. Photogramm. Eng. Remote Sens. 73(7):793804.

Reutebuch S, McGaughey R, Andersen H, Carson W (2003). Accuracy of a high-resolution LiDAR terrain model under a conifer forest canopy. Can. J. Remote Sens. 29(5):527-535.

Sanii S (2008). Assessing the effect of point density and terrain complexity on the quality of LiDAR-derived DEMs in multiple resolutions. Master on Geographic Information Systems, University of Calgary, Alberta, Canada, Available online: <http://people.ucalgary.ca/ mcdermid/Docs/Theses/Sanii_2008.pdf> (access on 7 December 2011).

Sheskin DJ (2007). Handbook of parametric and nonparametric statistical procedures. Ed: Chapman \& Hall/CRC (4th Ed.): London, England.

Silverman B (1986). Density estimation for statistics and data analysis. Ed: Chapman \& Hall: London, England.

Triglav-Cekada M, Crosilla F (2009). A simplified analytical model for apriori LiDAR point-positioning error estimation and review of LiDAR error sources. Photogramm. Eng. Remote Sens. 75(12):1425-1439.

Tukey JW (1977). Exploratory data analysis. Ed: Addison-Wesley Publishing Company: Reading, Massachusetts, USA.
Vosselman F, Klein K (2010). Visualisation and structuring of point clouds. In: Airborne and terrestrial laser scanning, Vosselman G, Maas $\mathrm{H}$, Ed: Whittles Publishing, Scotland. pp. 43-79.

Wang $Y$, Weinacker $H$, Koch B (2008). A LiDAR point cloud based procedure for vertical canopy structure analysis and 3D single tree modelling in forest. Sensors 8:3938-3951.

Su J, Bork E (2006). Influence of vegetation, slope and LiDAR sampling angle on DEM accuracy. Photogramm. Eng. Remote Sens. 72(11):1265-1274

Wehr A, Lohr U (1999). Airborne laser scanning-an introduction and overview. ISPRS J. Photogramm. 54(2-3):68-82

Yu X, Hyyppä J, Hyyppä H, Maltamo M (2004). Effects of flight altitude on tree height estimation using airborne laser scanning. In: Proceedings of ISPRS working group VIII/2 Laser-Scanners for Forest and Landscape Assessment, Albert Ludwigs University, Freiburg, Germany. pp. 96-101.

Yu X, Hyyppä H, Kaartinen H, Hyyppä J, Ahokas E, Kaasalainen S (2005). Applicability of first pulse derived digital terrain models for boreal forest studies. In: ISPRS (WG III/3, III/4, V/3) Workshop Laser scanning, Enschede, Netherlands. pp. 97-102. 